\title{
Frequency Alterations in Key Innate Immune Cell Components in the Peripheral Blood of Dengue Patients Detected by FACS Analysis
}

\author{
Jih-Jin Tsai ${ }^{a, c, d}$ Yen-Hua Jen ${ }^{c}$ Jung-San Chang ${ }^{b, c, e}$ Hui-Mien Hsiao ${ }^{f}$ \\ Sansanee Noisakran ${ }^{f, g}$ Guey Chuen Perng ${ }^{f}$
}

Divisions of ${ }^{\mathrm{a}}$ Infectious Diseases and ${ }^{\mathrm{b}}$ Gastroenterology, Department of Internal Medicine, and ${ }^{\mathrm{c}}$ Tropical Medicine Center, Kaohsiung Medical University Hospital, and Faculties of ${ }^{\mathrm{d}}$ Medicine and ${ }^{\mathrm{e}}$ Renal Care, College of Medicine, Kaohsiung Medical University, Kaohsiung, Taiwan, ROC; ${ }^{\mathrm{f}}$ Department of Pathology and Laboratory Medicine, Emory Vaccine Center, Emory University School of Medicine, Atlanta, Ga., USA; 9 Medical Biotechnology Unit, National Center for Genetic Engineering and Biotechnology, National Science and Technology Development Agency, Pathumthani, Thailand

\section{Key Words}

Dengue fever, hemorrhagic • Viremia - Thrombocytopenia • Innate Immunity

\begin{abstract}
Dengue is a timing disease, and frequently dengue patients do not seek help until 2-3 days after prodrome. Thus, the innate immune parameters in dengue patients remain largely unexplored. A comprehensive FACS profiling of key innate immune cells in the peripheral blood of dengue patients was performed. Twenty-seven dengue patients varying in days of fever onset were enrolled and the majority of them had primary infection based on serological results. FACS panels were used to evaluate NK cells, platelet-leukocyte aggregates (PLA), inflammatory monocytes, and plasmacytoid $(\mathrm{pDC})$ and myeloid dendritic cells (mDC). FACS results showed the following findings: (i) NK cells significantly dropped on day 5 after the onset of fever and gradually returned to normal within 2 weeks of illness; (ii) biphasic PLA were observed, maximum levels were reached on days 6-8
\end{abstract}

and 11-16, and platelet-monocyte aggregates (PMA) were the most frequent event; (iii) inflammatory monocytes were consistently lower on days 5-8 and gradually returned to the normal level in the second week of illness, and (iv) pDC reached the maximum level on day 5 and gradually declined to the baseline level after 1 week of illness. In contrast, mDC fluctuated somewhat during the first week of illness and returned to the baseline level in the second week of illness. The most interesting finding was the biphasic PLA, in particular the PMA. These innate immunological parameters could be a crucial factor dictating the complicated pathogenesis of dengue disease.

Copyright $\odot 2011$ S. Karger AG, Basel

\section{Introduction}

Innate immunity is the first line of the host's defense system against infections and it is the most well-conserved system across species. It covers a wide spectrum and includes the antigen-independent and fast immune

\section{KARGER}

Fax +4161306 1234

E-Mail karger@karger.ch

www.karger.com (c) 2011 S. Karger AG, Basel

$1662-811 \mathrm{X} / 11 / 0035-0530 \$ 38.00 / 0$

Accessible online at:

www.karger.com/jin
Dr. Guey Chuen Perng

Department of Pathology and Laboratory Medicine, Emory Vaccine Center Emory University School of Medicine, Dental School Building, Room 429 1462 Clifton Road, Atlanta, GA 30322 (USA)

Tel. +1 404727 5490, Fax +1 404712 9736, E-Mail gperng@emory.edu 
response in the host upon engagement with intruders. Its importance in the orchestration of a much more antigenspecific and effective adaptive immunity has been well established during the past several decades [1]. However, understanding the operational process of the innate immune system in human diseases is far more difficult than in a model system. This is partly due to the fact that humans often do not seek help until obvious clinical symptoms have evolved, which is a few days after the inception of infection. This is particularly true for certain infectious diseases such as dengue fever (DF), a mosquitoborne disease [2].

Dengue is one of the most important vector-borne human diseases. It is usually prevalent in tropical and subtropical regions but, over time, with multiple increasing factors such as global warming, unplanned urban development, and human mobilization, it has spread to almost every corner of the world and has thus become an emerging public health concern globally. A wide spectrum of clinical manifestations ranges from no symptoms and mild fever (DF) to a much more severe form, i.e. dengue hemorrhagic fever (DHF)/dengue shock syndrome, which is a life-threatening illness characterized by increased vascular permeability and plasma leakage [2]. There are 4 dengue serotypes (DENV-1 to DENV-4) and each serotype is capable of inducing severe dengue (DHF/ dengue shock syndrome). There is no vaccine or antiviral drug currently available to treat dengue and, therefore, supportive care is the main way to treat and improve patients' health.

Dengue is truly a timing disease. Patients often do not know they have been bitten by a mosquito carrying the infectious dengue virus until clinical signs develop, which is after a lapse of about 3-5 days and likely at the peak of viremia in circulation [3]. Thus, parameters related to innate immunity, such as cytokines and/or chemokines, are the dominant factors reported in specimens collected at the time of clinical onset and have often been linked to the outcomes of dengue [4-9]. Although there have been reports on the biomolecular properties linked to the involvement of the innate immune system in the setting of dengue, the nature of the contributing innate immune cells remains elusive.

In this report, we documented several key innate immune cells in the peripheral blood of dengue patients by flow cytometry (FACS) with established cell surface markers. Our results revealed that innate immunological parameters could be a crucial factor dictating the complicated pathogenesis of dengue disease.

Innate Immune Cells in Dengue Patients
Table 1. Panels of antibodies used in this study

\begin{tabular}{lllll}
\hline Markers & ${\text { Panel } 1^{\mathrm{a}}}$ & Panel $2^{\mathrm{b}}$ & ${\text { Panel } 3^{\mathrm{c}}}$ & Panel $^{\mathrm{d}}$ \\
\hline CD16 & FITC & & & FITC \\
CD19 & PE & & PE & \\
CD14 & PETxRD & PETxRD & & PETxRD \\
CD45 & PerCP & PerCP & & \\
CD4 & PECy7 & & & \\
CD56 & APC & & Alexa 700 & PerCP \\
CD3 & Alexa 700 & & & \\
CD8 & V450 & & & \\
CD61 & & FITC & & \\
CD62 & & PE & & \\
CD41 & & Alexa 647 & & PerCP \\
CD20 & & & PerCP & \\
CD27 & & & FITC & APC \\
CD38 & & & & PERCy7 \\
HLA-DR & & & & APC \\
CD123 & & & & V450 \\
CD11c & & & & \\
\hline
\end{tabular}

All antibodies were purchased from BD Biosciences.

a Panel 1 is to analyze general immune cells, B cells, T cells, and monocytes including NK cells.

b Panel 2 is to analyze activated platelet-leukocyte aggregates.

${ }^{\mathrm{c}}$ Panel 3 is to analyze plasmablast cells.

${ }^{\mathrm{d}}$ Panel 4 is to analyze inflammatory cells, $\mathrm{mDC}$, and $\mathrm{pDC}$.

\section{Subjects and Methods}

\section{Patient Recruitment}

This study was approved by the institutional review board of Kaohsiung Medical University Hospital (KMUH). We enrolled patients aged more than 15 years who visited KMUH and were diagnosed with acute dengue virus infection via laboratory confirmation or the Taiwan CDC according to WHO diagnostic guidelines [2]. The diagnosis was based on any of the following laboratory criteria: (a) dengue virus RNA was detected in serum; (b) the dengue virus was isolated from serum; (c) dengue NS1 antigen was detected, and (d) dengue virus-specific IgM and IgG antibodies were detected. Eight milliliters of blood was drawn from each enrolled subject for this study. From 2009 to the date of reporting, we collected 27 dengue cases. Blood from 4 healthy volunteers was used as the control in all studies. All patients whose blood was drawn had DF and did not have observable vascular leakage according to WHO diagnostic guidelines [2]. Liu's stain was used to examine blood smear slides as suggested by the manufacturer's protocol (Sigma). A complete blood count including hematocrit measurement was performed as previously described [10].

Serology and Virus Assays

IgM and IgG to the dengue virus were measured in all specimens by antibody capture enzyme immunoassay (EIA) as described previously $[11,12]$. The antibody measurement was per-

J Innate Immun 2011;3:530-540 
formed to confirm dengue virus infection and was not intended to differentiate between primary and secondary infections. Thus, all antibodies were measured at 1 time point. Reverse transcriptase-polymerase chain reaction (RT-PCR) was used to attempt to identify the infecting serotype in specimens as described previously [10].

\section{Flow Cytometry}

Antibody Panels for the Study

Four antibody panels were used to perform the gating strategy and identify the subpopulation of immune cells (table 1). Each panel was used to identify the particular immune cell population with its corresponding specific surface markers. A set of compensation for each panel was performed in parallel in all experiments.

Multiple Color Flow Cytometric Analysis

Five microliters of each antibody was dispensed into a specific labeled tube. One hundred microliters of whole blood sample was added to each antibody panel tube and into the corresponding compensation tube, respectively. Samples were gently mixed by vortex and incubated at room temperature for $15 \mathrm{~min}$ in the dark. Thereafter, $2 \mathrm{ml}$ of $1 \times$ Lysing Buffer (BD Biosciences, San Jose, Calif., USA) was added to each tube followed by gentle mixing and incubation at room temperature for $10 \mathrm{~min}$ in the dark. Following the incubation, samples were centrifuged at $500 \mathrm{rpm}$ at $4{ }^{\circ} \mathrm{C}$ for 5 min and then supernatants were decanted. Two milliliters of washing buffer (2\% FBS in PBS) was added to the samples followed by centrifugation at $1,200 \mathrm{rpm}$ at $4{ }^{\circ} \mathrm{C}$ for $5 \mathrm{~min}$. After supernatants had been decanted, $300 \mu \mathrm{l}$ of $1 \%$ paraformaldehyde in PBS was added to each sample and subjected to flow cytometry. Multiple color flow cytometric analysis was performed on an LSRII flow cytometer (BD Biosciences) using BD FACSDiva software (BD Biosciences). All data were analyzed using FlowJo software (Treestar, Inc., Ashland, Oreg., USA).

\section{Results}

The clinical demographics of the studied patients are shown in table 2 . The clinical history of older patients indicated that the majority of them had an underlying illness at the time of dengue presentation, while complications associated with dengue illness were common as previously reported $[2,13]$.

Typical blood mononuclear cells in dengue patients including the subset of lymphocytes and the main components of complete blood counts by FACS are tabulated in table 3. The counts of the platelets were at their lowest level on day 7 after illness (fig. 1a), while a steady increase in the hematocrit was registered (fig. 1b). A slight inverse relationship between the platelet counts and the hematocrit was observed. However, since activated platelets have a tendency to either aggregate or associate with leukocytes, the actual platelet counts may be underestimated. Serological results revealed that the majority of the den- gue cases were primary since $\operatorname{IgM}$ was the dominant antibody being detected, though 4 cases may likely have been secondary (fig. 2a, b). As plasma cells are an important immune component responsible for antibody production, it is reasonable to profile these cells in dengue patients. The strategy of identifying the plasma cells by FACS using established cell surface markers (table 1) is shown in figure $3 \mathrm{a}$. The plasmablast cells were defined as CD19+CD20-CD27+CD38+. A low frequency of plasmablast cells was registered in the majority of dengue cases (fig. 3b), though a few of the cases appeared to have levels above those of the healthy control, and 4 cases seemed to have a higher frequency compared to the rest of the cases. Coincidently, the 4 cases with higher plasma cell levels corresponded to those observed with higher IgG antibody titers (fig. 2b). In addition, RT-PCR revealed that 18 out of $27(67 \%)$ cases were dengue virus positive; 15 had DENV-2 and 3 had DENV-3, and 1 was co-infected with DENV-1.

Innate immunity plays a pivotal role in containing and controlling invaded pathogens. Although it is usually functioning at the beginning of the event, throughout the course of infection its effective role in fine tuning and orchestrating the overall immune response is still in play. Some of the key innate immune cells were therefore analyzed by FACS.

The gating strategy for profiling the natural killer (NK) cells by FACS is shown in figure $4 \mathrm{a}$. The NK cells were defined as CD45+CD19-CD3-CD56+. An up-anddown pattern was seen in CD56+ NK cells (fig. 4b) as well as in their subsets, i.e. CD56+CD16+ and CD56+CD16(fig. 4c). The fluctuation pattern was much more obvious in the CD56+CD16+ NK cells than in the CD56+CD16NK cells. In general, during the illness periods both CD56+ NK cell numbers and their CD56+CD16+ subpopulations were lower, while CD56+CD16- NK cell numbers appeared to be higher than those of the normal healthy control (fig. 4b, c).

Platelets have been integrated into the innate immune system. Although they are anuclear, platelets' powers in shaping and sharpening immunity have recently been noticed [14-17]. One of the key aspects of platelets is their capability to bind with leukocytes, and especially with monocytes, upon activation [18-20]. Thrombocytopenia is one of the clinical features of dengue patients and the majority of platelets are activated during the illness [21]. To see whether the low platelet counts observed in dengue patients are associated with aggregation with leukocytes, profiling of the platelet-leukocyte aggregates was performed as previously described [22] and the gating strat- 
Table 2. Demographic and clinical profiles of dengue patients

\begin{tabular}{|c|c|c|c|c|c|}
\hline $\begin{array}{l}\text { Patient } \\
\text { No. }\end{array}$ & $\begin{array}{l}\text { Age } \\
\text { years }\end{array}$ & Sex & DOF & Underlying diseases $^{\mathrm{a}}$ & Associated conditions \\
\hline 1 & 58 & M & 4 & GERD & Diarrhea \\
\hline 3 & 34 & M & 5 & & Hepatitis \\
\hline 4 & 57 & $\mathrm{~F}$ & 10 & & Nausea, vomiting, diarrhea \\
\hline 5 & 37 & $\mathrm{~F}$ & 5 & & \\
\hline 7 & 56 & M & 7 & Hyperlipidemia, TIA & \\
\hline 8 & 49 & $\mathrm{~F}$ & 16 & Hyperthyroidism & Nausea, vomiting \\
\hline 9 & 27 & $\mathrm{~F}$ & 11 & & Nausea, vomiting \\
\hline 10 & 45 & $\mathrm{~F}$ & 6 & $\begin{array}{l}\text { Cervical cancer, renal stones, Sicca } \\
\text { syndrome, rheumatoid arthritis }\end{array}$ & Hepatitis, GOT and GPT > $200 \mathrm{IU} / \mathrm{l}$ \\
\hline 11 & 66 & M & 6 & DM, CVD & Nausea, vomiting \\
\hline 16 & 74 & M & 8 & & \\
\hline 17 & 60 & M & 16 & & Nausea or vomiting, diarrhea \\
\hline 18 & 55 & $\mathrm{~F}$ & 11 & ATH S/P & \\
\hline 19 & 66 & $\mathrm{M}$ & 6 & CVA & Hepatitis \\
\hline 20 & 24 & M & 8 & & \\
\hline 21 & 35 & $\mathrm{~F}$ & 7 & & \\
\hline 22 & 24 & $\mathrm{~F}$ & 9 & & \\
\hline 23 & 49 & $\mathrm{M}$ & 7 & $\mathrm{DM}$ & \\
\hline 24 & 51 & $\mathrm{~F}$ & 5 & $\mathrm{HBV}$, thalassemia & \\
\hline 25 & 71 & $\mathrm{~F}$ & 9 & & \\
\hline 26 & 40 & $\mathrm{~F}$ & 6 & DM & Chest pain, nausea, vomiting \\
\hline
\end{tabular}

$\mathrm{DOF}=$ Day of fever on which the samples were collected for the study; GERD = gastroesophageal reflux disease; TIA = transient ischemic attack; $\mathrm{DM}=$ diabetes mellitus; $\mathrm{CVD}=$ cardiovascular disease; $\mathrm{ATH}=$ total abdominal hysterectomy; $\mathrm{S} / \mathrm{P}=$ status after operation; CVA = cerebrovascular accident; $\mathrm{HBV}=$ hepatitis B virus; GOT = glutamic-oxaloacetic transaminase; GPT = glutamic-pyruvic transaminase.

${ }^{a}$ History of diseases in patients prior to dengue virus infection.

Table 3. FACS profiling of immune cells in dengue patients

\begin{tabular}{|c|c|c|c|c|c|c|c|c|c|}
\hline DOF & 4 & 5 & 6 & 7 & 8 & 9 & 10 & 11 & 16 \\
\hline Cases, $\mathrm{n}$ & 3 & 4 & 4 & 3 & 3 & 4 & 1 & 2 & 3 \\
\hline B cells & $10.40 \pm 5.26^{\mathrm{a}}$ & $24.22 \pm 13.00$ & $26.06 \pm 16.43$ & $15.45 \pm 3.40$ & $14.87 \pm 1.22$ & $14.50 \pm 4.68$ & $11.97 \pm 0.00$ & $14.47 \pm 2.03$ & $16.25 \pm 5.94$ \\
\hline CD4 T cells & $27.46 \pm 6.01$ & $39.68 \pm 9.15$ & $24.58 \pm 4.77$ & $32.69 \pm 3.64$ & $33.5 \pm 10.01$ & $27.08 \pm 9.77$ & $21.01 \pm 0.00$ & $30.28 \pm 4.67$ & $28.74 \pm 2.08$ \\
\hline Monocytes & $5.72 \pm 3.44$ & $6.65 \pm 2.07$ & $7.31 \pm 2.19$ & $7.97 \pm 2.26$ & $12.37 \pm 1.24$ & $7.34 \pm 4.61$ & $19.56 \pm 0.00$ & $9.77 \pm 3.77$ & $7.31 \pm 1.82$ \\
\hline Granulocytes & $46.43 \pm 31.48$ & $54.06 \pm 9.25$ & $27.06 \pm 3.57$ & $27.52 \pm 5.38$ & $35.97 \pm 16.98$ & $50.37 \pm 11.84$ & $42.54 \pm 0.00$ & $48.35 \pm 3.02$ & $50.23 \pm 8.09$ \\
\hline Lymphocytes & $44.45 \pm 28.82$ & $37.74 \pm 9.28$ & $61.18 \pm 5.07$ & $57.86 \pm 8.04$ & $48.82 \pm 16.44$ & $36.09 \pm 9.04$ & $35.33 \pm 0.00$ & $39.30 \pm 1.31$ & $40.36 \pm 9.43$ \\
\hline
\end{tabular}

DOF $=$ Days of fever after the onset of fever. ${ }^{\text {a }}$ Percentage of gated cells \pm SEM. 
Fig. 1. Blood platelets and hematocrit in enrolled dengue patients. The measurements of platelet counts and the hematocrit are described in Subjects and Methods. a Actual platelet counts. The nadir of platelet counts was observed on day 7 after the onset of illness. b Hematocrit. A gradual increase in the hematocrit in dengue patients was registered.

Fig. 2. IgM and IgG in enrolled dengue patients. Dengue-specific IgM and IgG antibodies were measured from the serum of dengue patients as described in Subjects and Methods. a IgM titer. b IgG titer. The number on the y-axis indicates the antibody-converted unit as previously defined [3]. A higher IgM titer compared to the IgG titer was observed in most of the dengue patients.
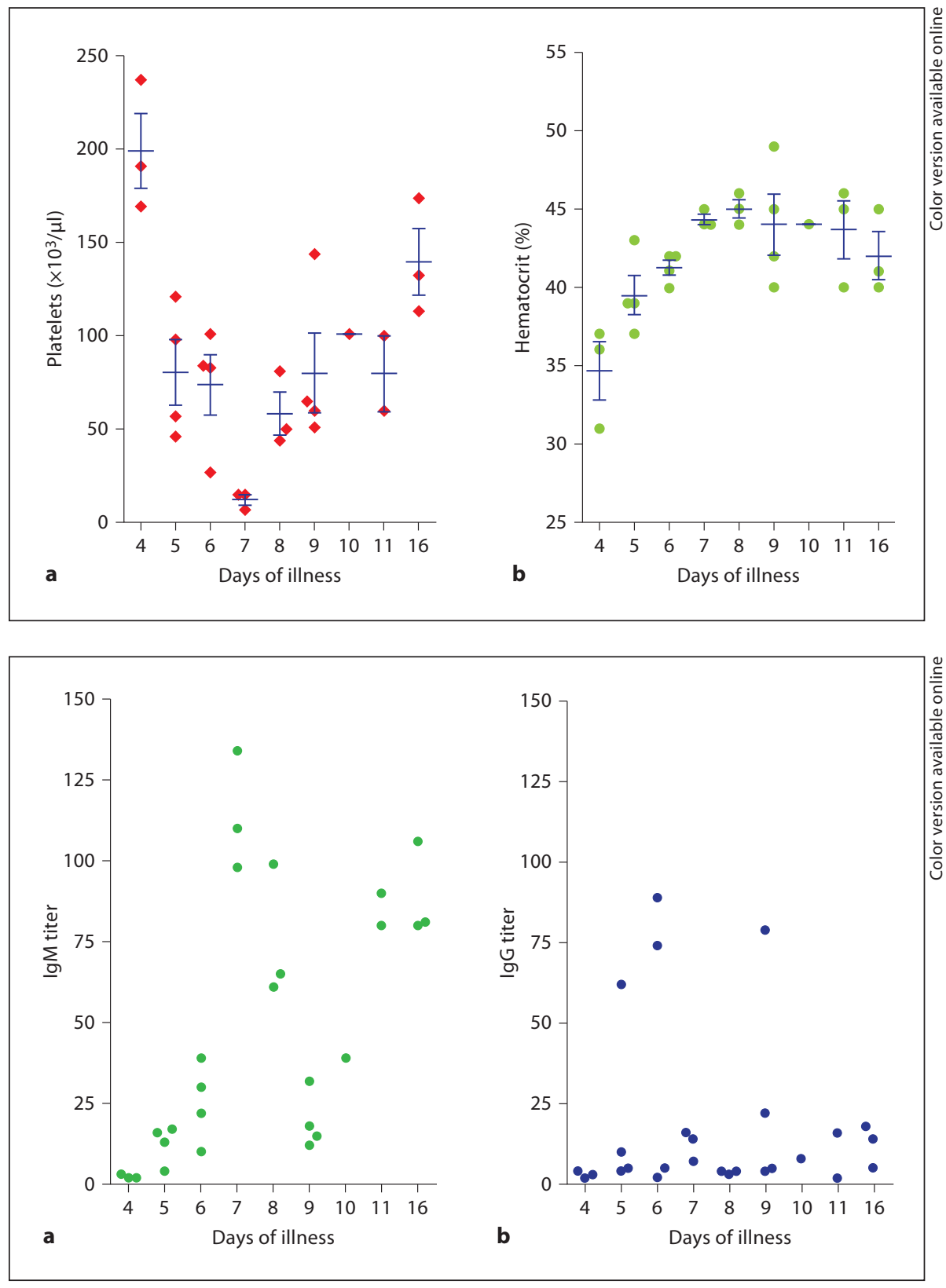

egy is shown (fig. 5a). Results revealed that biphasic aggregations occurred on days 6-8 and the second week after the onset of fever, and activated platelets were likely aggregated with leukocytes and in particular with monocytes (fig. 5b). The platelet-leukocyte aggregates were significantly higher in the biphasic periods in dengue patients compared to the normal healthy control (fig. 5b).

The overall monocytes did not change that much during the course of infection (table 3). There are at least 2 subsets of monocytes circulating in peripheral blood in the course of infection: classic monocytes (CD14+) and a subset of inflammatory monocytes (CD14+CD16+HLA$\mathrm{DR}+$ ) [23]. The gating strategy to identify the subset of inflammatory monocytes is presented in figure 6a. FACS profiling showed a U-shaped pattern in which the frequency of inflammatory monocytes was high in early infection and then dramatically decreased and gradually climbed back to the normal level of the healthy control 2 weeks after the onset of illness (fig. 6b). 


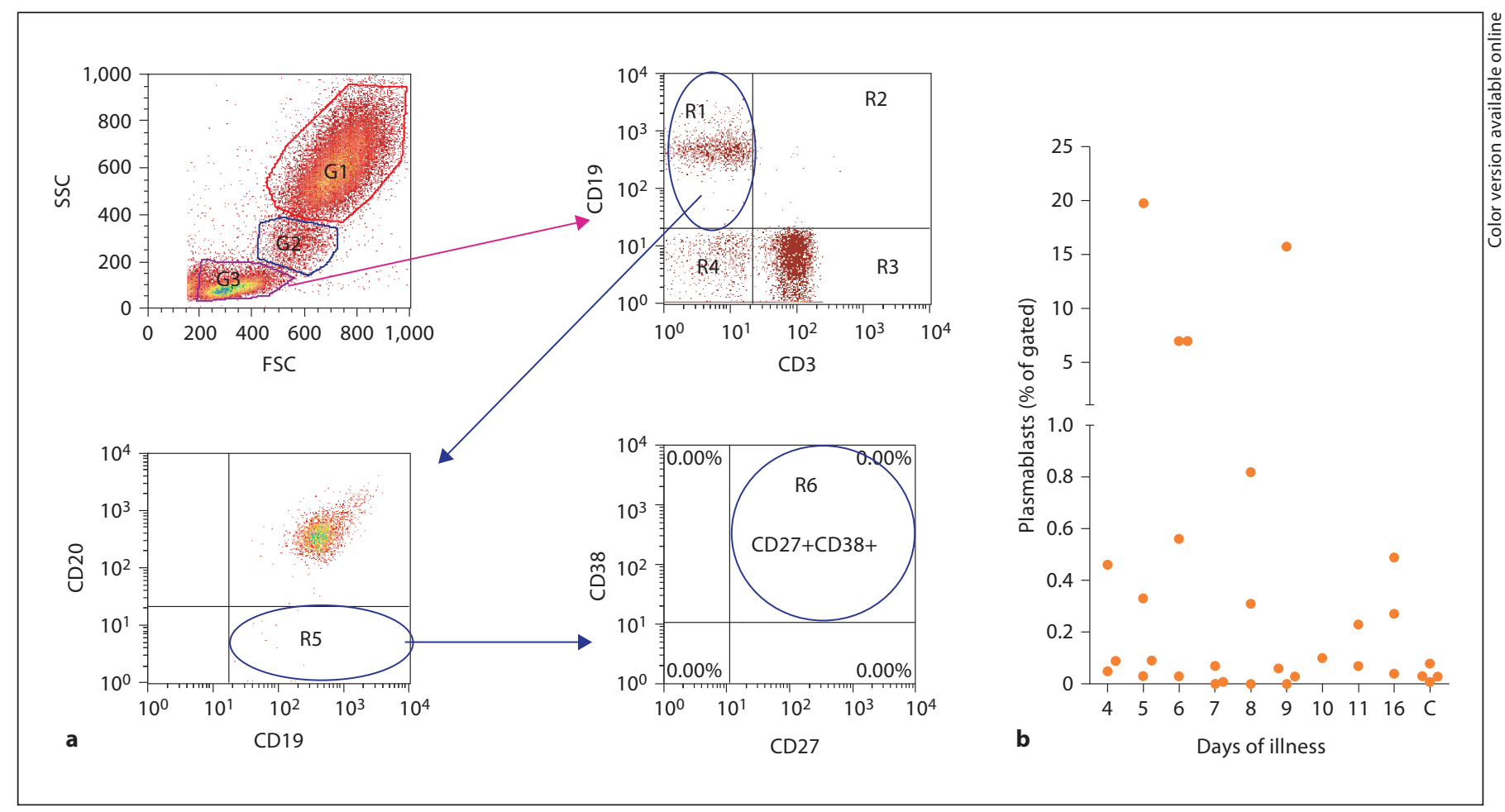

Fig. 3. Plasmablast profiling. a Gating strategy to identify the plasmablast. The G3 population was selected and analyzed for CD19+CD20-CD27+CD38+ cells (R6). b Frequency of plasmablast (R6). Only 4 patients had noticeable plasmablast, while few others were detectable compared to the healthy control. $\mathrm{C}=$ Healthy control.

Dendritic cells (DC) are much more effective innate immune cells in terms of bridging innate and adaptive immunities [23]. The best known DC types are myeloidderived $\mathrm{DC}(\mathrm{mDC})$ and plasmacytoid-derived DC (pDC), which are defined as CD14-HLA-DR+CD11c+CD123and CD14-HLA-DR+CD11c-CD123+, respectively [23]. The gating strategy to identify DC is shown in figure 7a. Results showed that fluctuation of mDC occurred early on during the course of infection while $\mathrm{pDC}$ peaked in a single day, 5 days after the onset of fever, as compared to the normal healthy control (fig. 7b).

\section{Discussion}

Innate immunity is the front line of the defense system in deterring any intruders. Its non-antigen-specific response provides an early platform for the host to fight against the intruder. Although reports on the potential role of innate immunity in dengue virus infection have occasionally been documented, these reports are pre- dominant in a specific subset of the innate immune system [24-27]. Thus, the role of the innate immune system in dengue virus infection remains a mystery. There are a few factors potentially contributing to this: (1) the time at which the dengue patient was bitten by a mosquito carrying the infectious dengue virus is very difficult to pinpoint; (2) dengue-affected patients often do not seek help or assistance until clinical symptoms arise, and (3) there is a lack of the perfect animal model that mimics the cardinal features of dengue patients.

Although limited numbers of dengue cases were reported in this study, these were predominantly primary dengue cases. This is significantly different from literature reports which are mainly of secondary dengue cases [25-28]. Thus, like in previous reports in which specimens were collected after prodrome, several key innate immune cells were documented by FACS in primary dengue-affected patients. Although with a limited number of dengue patients it was difficult to perform the statistical analysis, the most important findings were that the biological results were very consistent in these patients. This 
Fig. 4. NK cell profiling. a Gating strategy to profile the NK cells. The G3 population was selected and analyzed for total NK cells (CD45+CD3-CD19-CD56+; R5) and their subsets, i.e. CD45+CD3-CD19CD56+CD16- (R6) and CD45+CD3CD19-CD56+CD16+ (R7). b Total NK cells with CD56+ (R5). c Subsets of NK cells with CD56+CD16- (R6) and CD56+ CD16+ (R7). C = Healthy control.

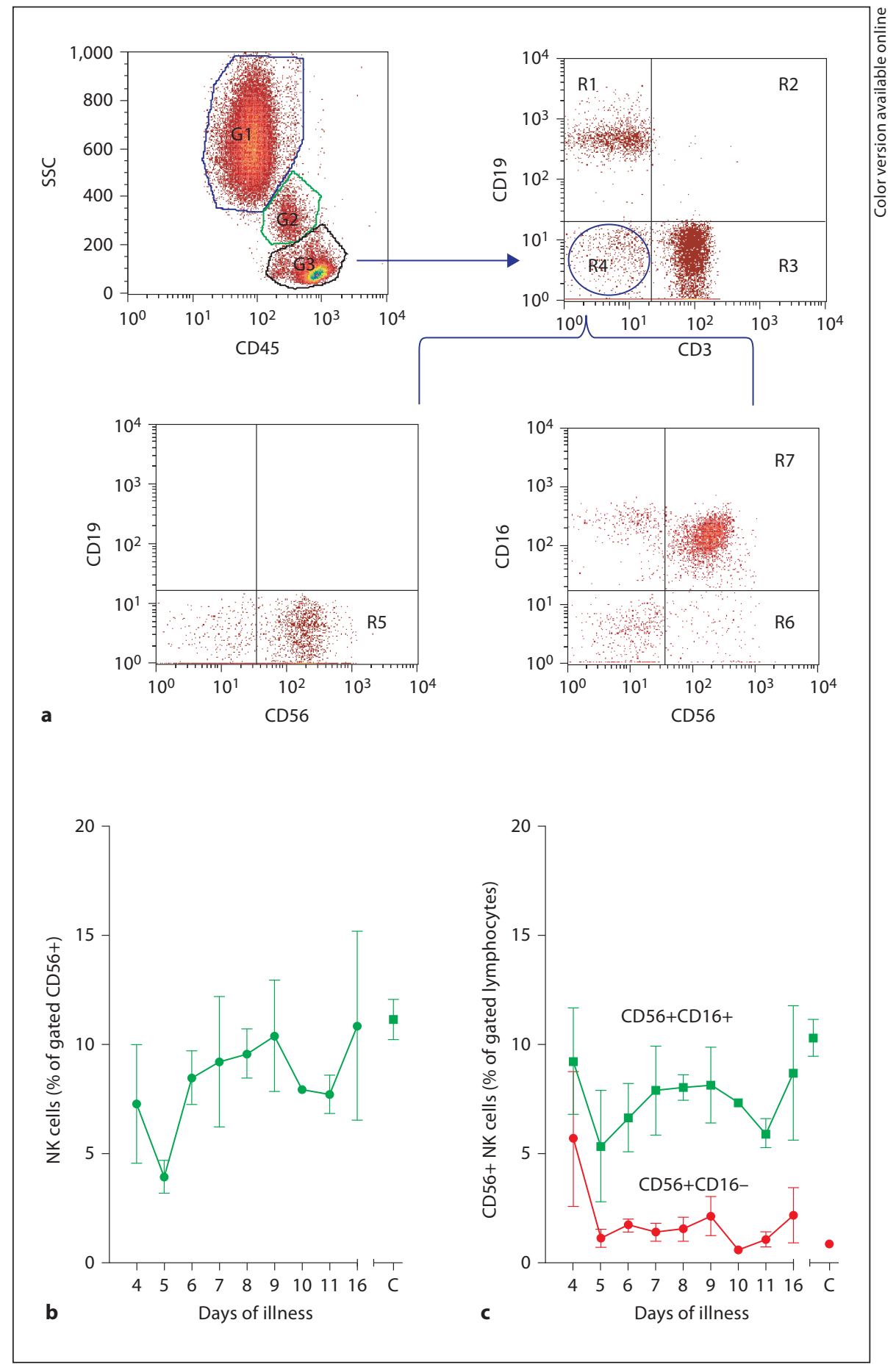

information may therefore be very useful and helpful for gaining a better understanding of the role of innate immunity in the pathogenesis of dengue.

The most significant finding of the current investigation was the platelet-leukocyte aggregates. It has been shown that activated platelets can bind with leukocytes and in particular with monocytes $[18,20]$. A very high percentage of activated platelets binding with monocytes was observed 6-8 days after the onset of fever, a time at which shock likely occurs. How and why the ac- 


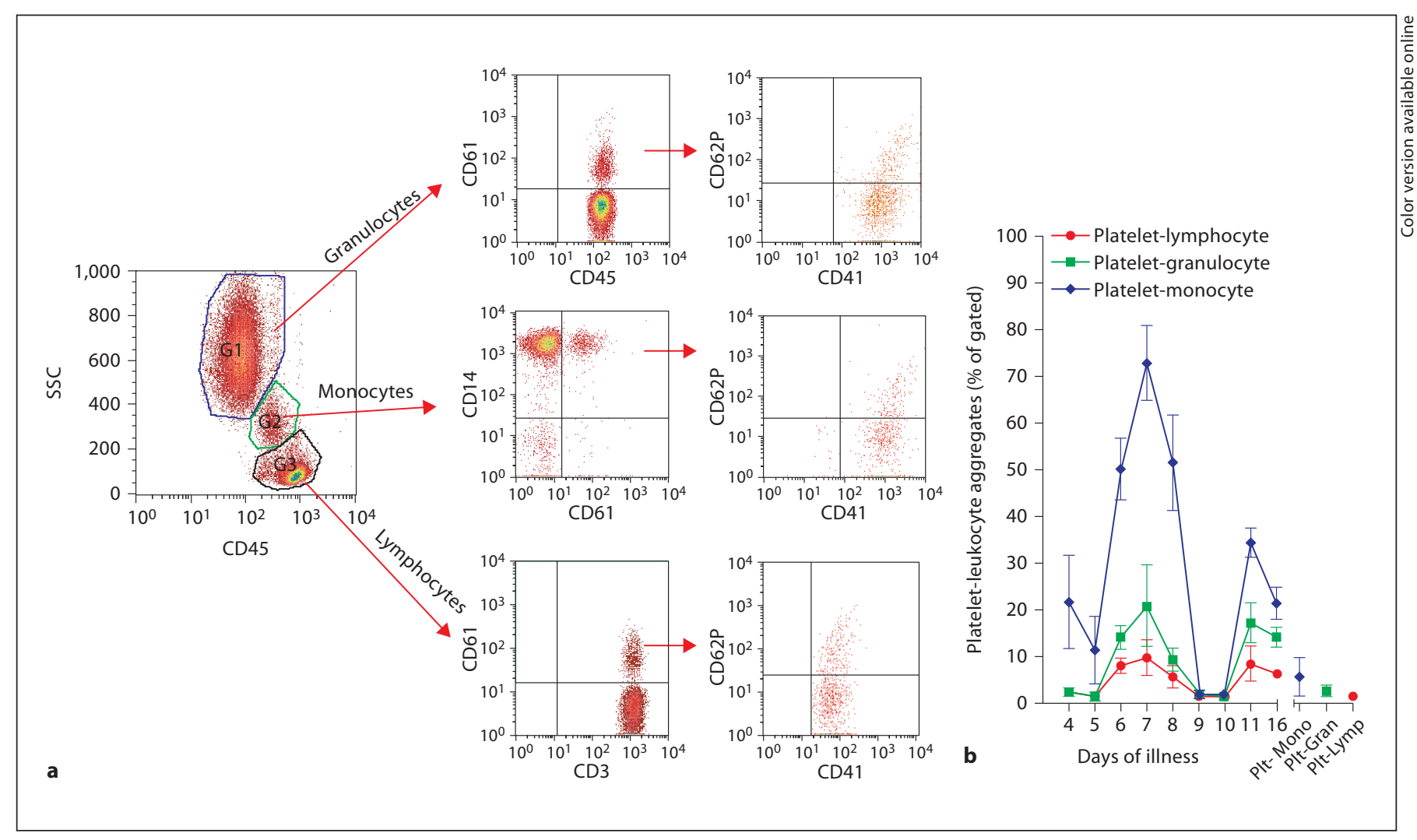

Fig. 5. Platelet-leukocyte aggregate profiling. The gating strategy was similar to that previously described [22] and a representation is shown (G1 for granulocytes, G2 for monocytes, and G3 for lymphocytes). An activated platelet marker, CD62P, in conjunction with specific leukocyte markers was used to profile the aggrega- tion by FACS. The fragmented axis next to the main frame represents the healthy control. Plt-Mono = Platelet-monocyte aggregates; Plt-Gran = platelet-granulocyte aggregates; Plt-Lymp = platelet-lymphocyte aggregates. tivated platelets aggregate so dramatically with monocytes is unknown at the moment. However, a few scenarios may account for this phenomenon: (i) dengue viral particles or antigens have been reported inside or on the surface of platelets, respectively [10, 29]; (ii) plateletassociated IgM or IgG has been observed in dengue patients [30, 31]; (iii) engulfment of dengue-containing platelets by monocytes has been observed in dengueinfected nonhuman primates [22], and (iv) dengue viral antigen-positive leukocytes are likely observed at the end of dengue viremia [32]. These reports suggest that monocytes are involved in the resolution of dengue virus infection via the phagocytosis of dengue virus-infected platelets. In addition, the observed phenomenon might occur and/or be enhanced in secondary infection. Interestingly, Honda et al. [30] recently demonstrated that the phagocytosis of platelets from patients with a secondary dengue virus infection is increased by human macrophages. Thus, the magnitude of the phagocytosis event may induce a large amount of cytokines/chemokines or other soluble factors released by monocytes, and this may trigger a sudden shock in dengue patients. However, the platelet-leukocyte aggregates were analyzed by FACS and the actual phagocytosis event was not observed [33]; therefore, this viewpoint still needs to be further investigated.

NK cells, whether a subset or not, did not appear significantly altered, though a moderate drop in the NK frequency 5 days after the onset of fever was observed. In general, the profiling results of NK cells were consistent with a previous report [34]. Interestingly, the observation that CD14+CD16+ inflammatory monocytes decrease 5-9 days after the onset of illness was unexpected, and it was similar to the observation by Azeredo et al. [34] in frozen specimens. It would be helpful if the current observation of PLA could be investigated further with a 


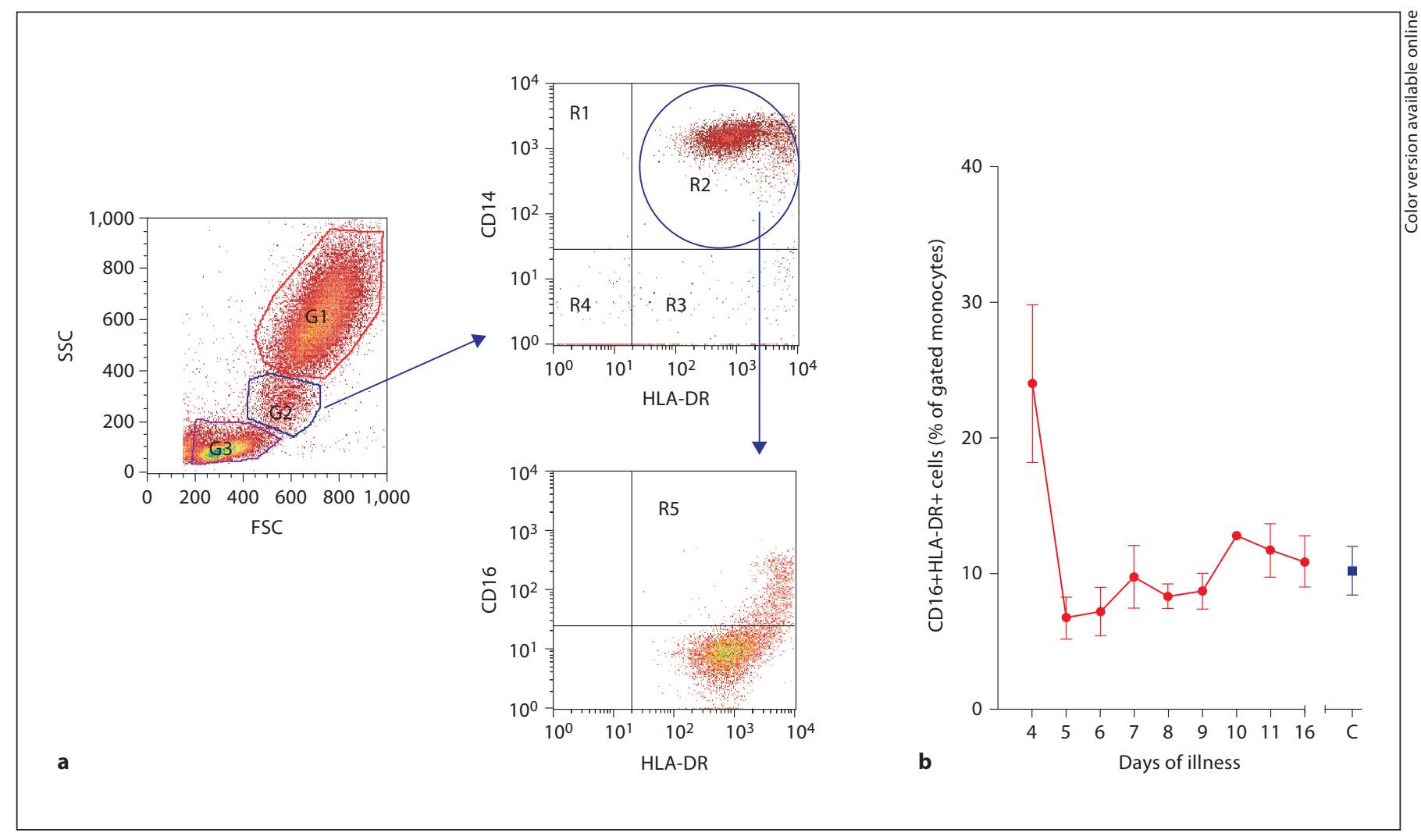

Fig. 6. Inflammatory monocyte profiling. a Gating strategy to identify the inflammatory monocytes. The G2 population was selected and analyzed for CD14+HLA-DR+CD16+ (R5). b Frequency of CD14+HLA-DR+CD16+. $\mathrm{C}=$ Healthy control.

suitable dengue animal model. In addition, since all of the patients had DF, we were unable to compare the levels of NK cells in DF to those in DHF as reported by Green et al. [35].

Dengue is a timing disease; thus, it is very difficult to obtain specimens early enough to determine the levels of $\mathrm{CD} 14+\mathrm{CD} 16+$ cells in the early days of infection. Interestingly, we did observe a high percentage of CD14+CD16+ cells on day 4 after the onset of illness, suggesting that these monocytes may be higher in the early days of infection. If this is the case, the results were consistent with studies showing large numbers of CD14+CD16+ monocytes circulating in the blood of patients with acute inflammation and infectious diseases [23]. In addition, since human CD14+CD16+ inflammatory monocytes are the key source of TNF- $\alpha$ production $[34,36,37]$, the lower levels of the CD14+CD16+ cells at later time points after infection may be due to an immune controlling program implemented in dengue patients to mitigate potential harmful side effects.
A low percentage of $\mathrm{mDCs}$ and $\mathrm{pDCs}$ circulate in the peripheral blood of normal healthy humans [23]. mDCs express class II antigen and CD11c and are important for the stimulation of $\mathrm{T}$ cell proliferation, while $\mathrm{pDCs}$ are the most potent IFN- $\alpha$-producing cells in response to viral pathogens [23]. Thus, $\mathrm{mDC}$ and $\mathrm{pDCs}$ are critical in fine tuning host immunity to fend off residues of the virus. The observation of fluctuating $\mathrm{mDCs}$ in dengue patients may likely be due to the migration of mDCs in and out of the vascular system and the carrying of antigens to secondary lymphoid organs to initiate the fine tuning of the immune response to dengue viral antigens [38]. IFN- $\alpha$ has been demonstrated to be an important cytokine in controlling the dengue virus $[39,40]$. Thus, the transient peak of pDCs on day 5 after the onset of fever may likely be related to the tight regulatory program in $\mathrm{pDCs}$ and its short life span in circulation [23]. However, since we only had 3 or 4 patients at each time point, an evaluation of the actual trend of the DCs is improbable. Consequently, the behavior of DCs in vivo could not be predicted 


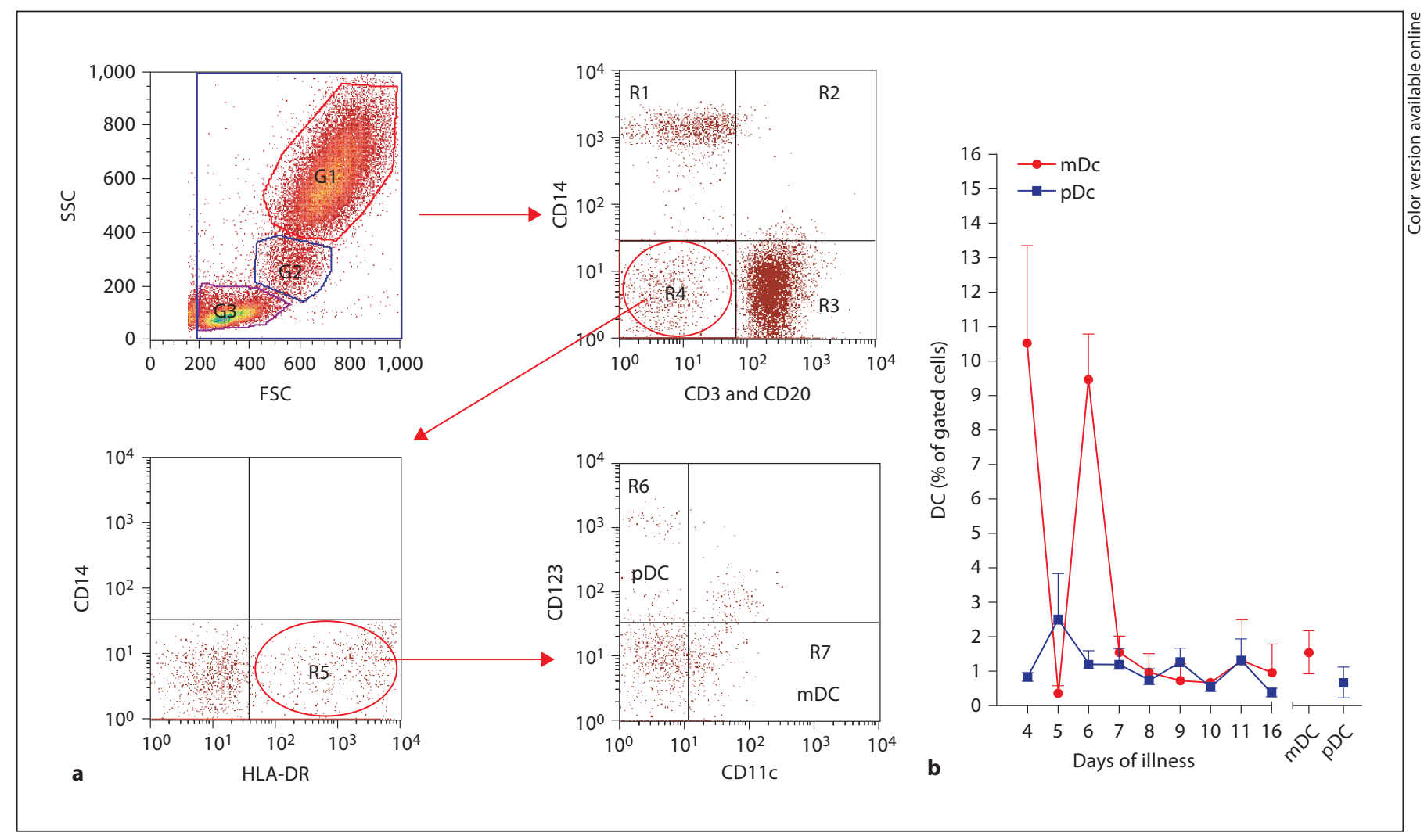

Fig. 7. $\mathrm{DC}$ profiling. a Gating strategy to profile $\mathrm{pDC}$ and $\mathrm{mDC}$. The stained cells $(\mathrm{G} 1+\mathrm{G} 2+\mathrm{G} 3)$ were analyzed for CD3-CD20-CD14-HLA-DR+CD123+CD11c- cells (pDC) (R6) and CD3-CD20-CD14-HLA-DR+CD123$\mathrm{CD} 11 \mathrm{c}+$ cells $(\mathrm{mDC})(\mathrm{R} 7)$. b Frequency of $\mathrm{pDC}$ and $\mathrm{mDC}$. The fragmented axis next to the frame represents the healthy control.

since they may migrate in and out of circulation and tissue. The status of DCs in dengue patients warrants more investigation.

Taken together, our findings suggest that dynamic innate factors may be important in the pathogenesis dengue and warrant further investigation.

\section{Acknowledgements}

We would like to thank the clinical staff at the Tropical Medicine Center and Division of Infectious Diseases of Kaohsiung Medical University Hospital. This study was supported by an Emory SOM start-up fund and by a Taiwan National Science Council Research Grant.

\section{References}

Innate Immune Cells in Dengue Patients
1 Kindt TA, Goldsby R, Osborne B: Kuby Immunology, ed 6. New York, W.H. Freeman, 2006.

2 World Health Organization: Dengue haemorrhagic fever: diagnosis, treatment, prevention and control, ed 2. Geneva, WHO, 1997.

- 3 Vaughn DW, Green S, Kalayanarooj S, Innis BL, Nimmannitya S, Suntayakorn S, Endy TP, Raengsakulrach B, Rothman AL, Ennis FA, Nisalak A: Dengue viremia titer, antibody response pattern, and virus serotype correlate with disease severity. J Infect Dis 2000;181:2-9. 
6 King CA, Marshall JS, Alshurafa H, Anderson R: Release of vasoactive cytokines by antibody-enhanced dengue virus infection of a human mast cell/basophil line. J Virol 2000; 74:7146-7150.

7 Chaturvedi UC, Elbishbishi EA, Agarwal R, Raghupathy R, Nagar R, Tandon R, Pacsa AS, Younis OI, Azizieh F: Sequential production of cytokines by dengue virus-infected human peripheral blood leukocyte cultures. J Med Virol 1999;59:335-340.

-8 Gubler DJ: Dengue and dengue hemorrhagic fever. Clin Microbiol Rev 1998;11:480-496.

-9 Navarro-Sanchez E, Despres P, Cedillo-Barron L: Innate immune responses to dengue virus. Arch Med Res 2005;36:425-435.

10 Noisakran S, Gibbons RV, Songprakhon P, Jairungsri A, Ajariyakhajorn C, Nisalak A, Jarman RG, Malasit P, Chokephaibulkit K, Perng GC: Detection of dengue virus in platelets isolated from dengue patients. Southeast Asian J Trop Med Public Health 2009;40:253-262.

-11 Vaughn DW, Green S, Kalayanarooj S, Innis BL, Nimmannitya S, Suntayakorn S, Rothman AL, Ennis FA, Nisalak A: Dengue in the early febrile phase: viremia and antibody responses. J Infect Dis 1997;176:322-330.

12 Innis BL, Nisalak A, Nimmannitya S, Kusalerdchariya S, Chongswasdi V, Suntayakorn S, Puttisri P, Hoke CH: An enzymelinked immunosorbent assay to characterize dengue infections where dengue and Japanese encephalitis co-circulate. Am J Trop Med Hyg 1989;40:418-427.

13 World Health Organization: Dengue and dengue hemorrhagic fever. Geneva, WHO, 2009, p 117.

14 Leslie M: Cell biology: Beyond clotting - the powers of platelets. Science 2010;328:562564.

15 Semple JW, Freedman J: Platelets and innate immunity. Cell Mol Life Sci 2009;67:499511.

16 von Hundelshausen P, Weber C: Platelets as immune cells: bridging inflammation and cardiovascular disease. Circ Res 2007;100: 27-40.

-17 Youssefian T, Drouin A, Masse JM, Guichard J, Cramer EM: Host defense role of platelets: Engulfment of HIV and Staphylococcus aureus occurs in a specific subcellular compartment and is enhanced by platelet activation. Blood 2002;99:4021-4029.

18 Furman MI, Kereiakes DJ, Krueger LA, Mueller MN, Pieper K, Broderick TM, Schneider JF, Howard WL, Fox ML, Barnard MR, Frelinger AL 3rd, Michelson AD: Leukocyte-platelet aggregation, platelet surface P-selectin, and platelet surface glycoprotein IIIa after percutaneous coronary intervention: effects of dalteparin or unfractionated heparin in combination with abciximab. Am Heart J 2001;142:790-798.
19 Gawaz MP, Mujais SK, Schmidt B, Gurland HJ: Platelet-leukocyte aggregation during hemodialysis. Kidney Int 1994;46:489-495.

20 Boilard E, Nigrovic PA, Larabee K, Watts GF Coblyn JS, Weinblatt ME, Massarotti EM, Remold-O’Donnell E, Farndale RW, Ware J, Lee DM: Platelets amplify inflammation in arthritis via collagen-dependent microparticle production. Science 2010;327:580-583.

21 Srichaikul T, Nimmannitya S: Haematology in dengue and dengue haemorrhagic fever. Baillieres Best Pract Res Clin Haematol 2000;13:261-276.

22 Onlamoon N, Noisakran S, Hsiao HM, Duncan A, Villinger F, Ansari AA, Perng GC: Dengue virus-induced hemorrhage in a nonhuman primate model. Blood 2010;115: 1823-1834.

23 Auffray C, Sieweke MH, Geissmann F: Blood monocytes: development, heterogeneity, and relationship with dendritic cells. Annu Rev Immunol 2009;27:669-692.

24 Avirutnan P, Mehlhop E, Diamond MS: Complement and its role in protection and pathogenesis of flavivirus infections. Vaccine 2008;26(suppl 8):I100-I107.

25 Azeredo EL, De Oliveira-Pinto LM, Zagne SM, Cerqueira DI, Nogueira RM, Kubelka CF: NK cells, displaying early activation, cytotoxicity and adhesion molecules, are associated with mild dengue disease. Clin Exp Immunol 2006;143:345-356.

26 Loke P, Hammond SN, Leung JM, Kim CC, Batra S, Rocha C, Balmaseda A, Harris E: Gene expression patterns of dengue virusinfected children from Nicaragua reveal a distinct signature of increased metabolism. PLoS Negl Trop Dis 2010;4:e710.

27 Ubol S, Masrinoul P, Chaijaruwanich J, Kalayanarooj S, Charoensirisuthikul T, Kasisith J: Differences in global gene expression in peripheral blood mononuclear cells indicate a significant role of the innate responses in progression of dengue fever but not dengue hemorrhagic fever. J Infect Dis 2008;197: 1459-1467.

28 Fink J, Gu F, Ling L, Tolfvenstam T, Olfat F, Chin KC, Aw P, George J, Kuznetsov VA, Schreiber M, Vasudevan SG, Hibberd ML: Host gene expression profiling of dengue virus infection in cell lines and patients. PLoS Negl Trop Dis 2007; 1:e86.

29 Noisakran S, Chokephaibulkit K, Songprakhon P, Onlamoon N, Hsiao HM, Villinger F, Ansari A, Perng GC: A re-evaluation of the mechanisms leading to dengue hemorrhagic fever. Ann NY Acad Sci 2009;1171(suppl 1):E24-E35.
30 Honda S, Saito M, Dimaano EM, Morales PA, Alonzo MT, Suarez LA, Koike N, Inoue S, Kumatori A, Matias RR, Natividad FF, Oishi K: Increased phagocytosis of platelets from patients with secondary dengue virus infection by human macrophages. Am J Trop Med Hyg 2009;80:841-845.

31 Saito M, Oishi K, Inoue S, Dimaano EM, Alera MT, Robles AM, Estrella BD Jr, Kumatori A, Moji K, Alonzo MT, Buerano CC, Matias RR, Morita K, Natividad FF, Nagatake T: Association of increased platelet-associated immunoglobulins with thrombocytopenia and the severity of disease in secondary dengue virus infections. Clin Exp Immunol 2004;138:299-303

32 Marchette NJ, Halstead SB, Falkler WA Jr, Stenhouse A, Nash D: Studies on the pathogenesis of dengue infection in monkeys. 3 . Sequential distribution of virus in primary and heterologous infections. J Infect Dis 1973;128:23-30.

33 Sarma J, Laan CA, Alam S, Jha A, Fox KA, Dransfield I: Increased platelet binding to circulating monocytes in acute coronary syndromes. Circulation 2002; 105:21662171.

34 Azeredo EL, Neves-Souza PC, Alvarenga AR, Reis SR, Torrentes-Carvalho A, Zagne SM, Nogueira RM, Oliveira-Pinto LM, Kubelka CF: Differential regulation of tolllike receptor-2, toll-like receptor-4, CD16 and human leucocyte antigen-DR on peripheral blood monocytes during mild and severe dengue fever. Immunology 2010;130: 202-216.

-35 Green S, Pichyangkul S, Vaughn DW, Kalayanarooj S, Nimmannitya S, Nisalak A, Kurane I, Rothman AL, Ennis FA: Early cd69 expression on peripheral blood lymphocytes from children with dengue hemorrhagic fever. J Infect Dis 1999;180:1429-1435.

36 Gordon S, Taylor PR: Monocyte and macrophage heterogeneity. Nat Rev Immunol 2005;5:953-964.

37 Soehnlein O, Lindbom L: Phagocyte partnership during the onset and resolution of inflammation. Nat Rev Immunol 2010;10: 427-439.

38 Coombes JL, Robey EA: Dynamic imaging of host-pathogen interactions in vivo. Nat Rev Immunol 2010;10:353-364.

39 Kurane I, Innis BL, Nimmannitya S, Nisalak A, Meager A, Ennis FA: High levels of interferon alpha in the sera of children with dengue virus infection. Am J Trop Med Hyg 1993;48:222-229.

40 Diamond MS, Harris E: Interferon inhibits dengue virus infection by preventing translation of viral RNA through a PKR-independent mechanism. Virology 2001;289:297311. 